\title{
INNOVATION STRATEGIES IN A COMPETITIVE DYNAMIC SETTING
}

\author{
RUSLAN LUKACH \\ JOSEPH PLASMANS \\ PETER M. KORT
}

CESIFO WORKING PAPER NO. 1395

CATEGORY 9: INDUSTRIAL ORGANISATION

FEBRUARY 2005

\footnotetext{
An electronic version of the paper may be downloaded

- from the SSRN website:

www.SSRN.com

- from the CESifo website:

www.CESifo.de
} 


\title{
INNOVATION STRATEGIES IN A COMPETITIVE DYNAMIC SETTING
}

\begin{abstract}
This paper presents a dynamic model of a competitive $R \& D$ and production duopoly subject to knowledge spillovers. Two asymmetric firms operate for a limited period of time and dispose their knowledge capital in the end. Both firms and the social planner prefer the R\&Dcooperative strategy over the competitive one regardless of the intensity of knowledge spillovers. Accumulation of knowledge capital results allows the monopolist to have lower marginal cost of production and charge a lower market price than a fully competitive duopoly. Being able to define the degree of knowledge exchange when creating a research joint venture, the firms do not necessary choose the highest degree of cooperation available.
\end{abstract}

JEL Code: C72, D21, O31.

Keywords: innovation, $R \& D$, spillovers, cooperation.

\author{
Ruslan Lukach \\ University of Antwerp \\ Department of Economics \\ Prinsstraat 13 \\ 2000 Antwerp \\ Belgium \\ ruslan.lukach@ua.ac.be
}

\author{
Joseph Plasmans \\ University of Antwerp \\ Department of Economics \\ Prinsstraat 13 \\ 2000 Antwerp \\ Belgium \\ joseph.plasmans@ua.ac.be
}

Peter M. Kort

Tilburg University

Department of Econometrics \& Operations Research

5000 LE Tilburg

The Netherlands

kort@uvt.nl 


\section{Introduction}

The objective of this study is to investigate strategic $R \& D$ and production behavior of asymmetric agents in a dynamic setting. It is assumed that the knowledge spillovers exist and we consider scenarios where firms cooperate in $\mathrm{R} \& \mathrm{D}$ and/or production with an innovative technology. The study is based on the static competitive behavior model in d'Aspremont and Jacquemin's (1988) (referred below as A\&J (88)). The A\&J (88) model was subject to a number of extensions and modifications, most of which were built in a similar static setup (Suzumura (1992), Vonortas (1994), Brod and Shivakumar (1997), Kamien and Zang (2000)) The A\&J(88) model was also extended (by Hinloopen (2000)) to analyze the policy instruments regulating the firms' innovation activities.

We find that a dynamic setting is more interesting, because it requires agents to learn and accumulate the knowledge capital and build their strategies with an account of the time factor (Reinganum (1981) and Doraszelski (2003)). Previously, a dynamic extension to the A\&J(88) was provided by Petit and Tolwinski (1999). They assume in their model that firms have a linear knowledge capital accumulation path, controlled by the knowledge capital investment rates. A case of firms with asymmetric knowledge accumulation capacity is also considered.

Nonetheless, the Petit and Tolwinski's model cannot be viewed as a direct dynamic extension of the original static model. Unlike in A\&J(88), Petit and Tolwinski used a nonlinear demand function and a number of implicit nonlinear evolution parameters in the research cost function and the knowledge capital growth, which is a difficult nonlinear optimization problem. Moreover, the conclusions derived from this study do not utilize the dynamic features of the model and concentrate on the aspects similar to those studied in the static-type papers.

In our study we preserve all the initial assumptions of $A \& J(88)$, but use our own asymmetric setup, where one firm is capable of producing and innovating more efficiently than the other. Technically, this model is a dynamic game with two state variables (quantities of knowledge capital accumulated by two agents) and four control variables (each agent's $R \& D$ investment and production volumes). We employ dynamic game methods together with numerical simulation techniques (based on the dynamic programming methodology of Kendrick (1987)) to obtain solutions and draw the firms' time paths. The solution of this model is a feedback Nash equilibrium of a linear-quadratic difference game.

In our research we succeeded in achieving a number of important results describing the dynamic aspects of strategic cooperative/competitive R\&D. We observed that the outcomes of the firm's strategic choice in the beginning of the dynamic game do not necessary indicate in favor of a strategy, which is optimal for the game in overall. The profits of fully competing firms in the beginning of the game are higher than the profits with knowledge sharing or those of the research joint venture, but this situation changes in time. If a total net present value of profits is considered, $\mathrm{R} \& \mathrm{D}$ cooperation and knowledge sharing are more efficient strategies than full competition. 
The ability of the firm to accumulate knowledge over time plays important role in determining the market's performance. When the knowledge capital of the firm(s) becomes substantial enough, it is possible to observe the cases when a monopoly results in a lower market price and marginal production cost, than in the case of fully competing firms.

The factor of knowledge spillovers attributes to the fact that one firm can freely benefit from R\&D conducted by another firm. The general consensus is that when knowledge spillovers are strong, the innovating firms have greater incentives to cooperate, which is also socially desirable. The initial A\&J(88) model supports this conclusion in a static setting. Our goal is to figure out how the picture changes over time if the agents are allowed to play their game dynamically.

An RJV with fully internalized spillovers is well studied in the literature Vonortas (1994), Suzumura (1992), Kamien and Zang (2000), Hinloopen(2000). They assume that when two firms decide to cooperate in R\&D the knowledge is completely shared by the members of the consortium.

In our study we allow firms to determine the degree of their cooperation in research by setting an arbitrary degree of knowledge exchange, which can be higher than the existing knowledge spillover factor, but yet lower than one observed when the knowledge is fully shared. In this context we can reinterpret the findings of the static A\&J(88) model in a following way: firms' cooperative profits are the highest when firms decide to share the knowledge completely. The study of Amir et. al (2003) considered the partially endogenized spillovers in a generalized static setup. Their finding is that the firms will create make a cooperative agreement only in two circumstances: either with full knowledge exchange or without any additional exchange of knowledge other then through the existing spillovers effect. In our dynamic setting the results are different.

The model indicates that in the situation when "natural" knowledge spillovers are extremely weak, a more efficient firm experiences decreasing cooperative profits for the range of weaker cooperative arrangements (when the degree of knowledge exchange is higher than that of natural spillovers, but still low enough) and an increasing profits after a certain threshold value. Only cooperative agreements with a strong degree of knowledge exchange above the threshold value provide a more efficient player with increasing profits.

The paper is organized as follows. Section 2 presents the reader with a dynamic strategic model of cooperative/competitive R\&D and production. In Section 3 we give the results of numerical simulations. And Section 4 concludes the paper.

\section{The Model}

Two firms operate in the same market with the normalized reverse demand function at time period $t$ :

$$
p_{t}=1-Q_{t},
$$


where

$$
Q_{t}:=q_{i, t}+q_{j, t}, \quad t \in[0, T], \quad i, j=1,2, \quad i \neq j,
$$

is the overall or industry production at time $t$ of two agents together.

We define a final time period $T$, where the firms terminate their game under given conditions. This end period can mark various termination conditions for innovation. In her model Reinganum (1981) calls this time moment a Doomsday and describes it as the moment when invention becomes completely obsolete or when the R\&D is abandoned due to the failure to obtain a new technology. In our case the termination condition implies that any further perfection of the current technological process is no longer possible. We also assume that in the end of the game the knowledge capital is not rendered completely useless, but is sold out, meaning that this knowledge can be used to improve other technologies.

There are two corner stones in the A\&J(88) model. One is a quadratic research cost function, which allows for diminishing returns to R\&D. And the second is the implicit effect of one firm's R\&D on the production costs of the other. A particular firm's R\&D cost function at time $t$ is:

$$
C_{i}^{r}\left(x_{i, t}\right)=\gamma_{i} \frac{x_{i, t}^{2}}{2}, \quad i=1,2,
$$

where $\gamma_{i}>0$ is agent $i$ 's per-unit marginal cost of research and $x_{i, t}$ is firms $i$ 's amount of R\&D effort directed at reducing the marginal cost of production. Two asymmetric agents have $\gamma_{i} \neq \gamma_{j}, i=1,2, \quad i \neq j$.

Agent $i$ 's production cost function at moment $t$ is:

$$
C_{i}\left(q_{i, t}, k_{i, t}, k_{j, t}\right)=\left(A_{i}-k_{i, t}-\beta k_{j, t}\right) q_{i, t}, \quad i, j=1,2, \quad i \neq j,
$$

where $0<A_{i}<a$, is agent $i$ 's marginal cost of production when there is no $\mathrm{R} \& \mathrm{D}$ conducted and the condition implies that the intercept of the inverse demand function is higher than the highest value of the marginal cost. Variable $k_{i, t}$, $i, j=1,2, \quad i \neq j$, represents the current level of firm $i$ 's accumulated knowledge capital at time period $t$. The corresponding knowledge capital evolution equation is a linear function of previous state and current R\&D expenditures:

$$
k_{i, t}=(1-d) k_{i, t-1}+x_{i, t},
$$

where $d$ is the linear depreciation rate for the knowledge capital. In the production cost function the parameter $\beta \in[0,1]$ represents the knowledge spillover effect. Parameter $\beta$ describes how intensive firm $i$ 's production cost is decreased by the firm $j$ 's research efforts without any direct remuneration of firm $i$ to firm $j$.

There are two more conditions, which bring the model in line with the market reality. The first condition implies that the marginal production cost is always non-negative

$$
k_{i, t}+\beta k_{j, t} \leq A_{i}, \text { for } \forall t \in[0, T], i, j=1,2, i \neq j .
$$


And the second gives us non-negative price in the market:

$$
Q_{t}<1, t \in[0, T] .
$$

We assume that agents are fully asymmetric, i.e. agent 1 has an advantage in both research and production cost functions over agent 2 . The difference in $\mathrm{R} \& \mathrm{D}$ and production capacity is reflected by having different values of $A \mathrm{~s}$ and $\gamma \mathrm{s}$ for different agents. Assuming that firm 1 is a bigger firm, it follows that

$$
A_{1}<A_{2}
$$

and

$$
\gamma_{1}<\gamma_{2},
$$

i.e. we expect that the bigger agent has a lower marginal cost of production and also a lower per unit marginal cost of research. The cross-costs advantages are also possible, but we refrain from studying these scenarios here. Both agents maximize their profit functions (discounted by the factor $0<\rho<<1$ ) over a fixed period of time

$$
t \in[0, T],
$$

subject to the start-point and the end-point conditions: $k_{i, 0}=0, k_{i, T}=$ free . At every moment in time the firms play a two-stage game. In the first stage they make decisions about the amount of their their R\&D efforts. In the second stage the agents build their profit maximizing production plans. As it is show below, only the first stage game is directly linked to the dynamic behavior of the agents, while the solution logic in the second stage game is the same as in the static case. Similarly to the static model, we consider three major modes of cooperation between the two agents in the observed industry: i) competition between the agents in both research and production stages. (denoted shortly as (NC, NC) mode), ii). cooperation between the agents in research, but competition in production $((\mathrm{C}, \mathrm{NC})$ mode $)$, iii) cooperation between the agents in both research and production $((\mathrm{C}, \mathrm{C})$ mode). In this particular study we assume that the mode decision is made beforehand and the agents can not switch the mode after the game has started (full commitment).

\subsection{Non-Cooperative Duopoly (NC, NC)}

In this mode firms decide to behave competitively in both $R \& D$ and production. As we solve the problem backwards, we start with considering the second stage game, where firms both maximize the total accumulated profit function:

$$
\begin{aligned}
\max _{\left\{q_{i, t}\right\}} \pi_{i}= & \pi_{i, T}\left(k_{i, T}, k_{j, T}\right)+ \\
& \sum_{t=0}^{T-1}(1+\rho)^{-t}\left[\left(1-\left(q_{i, t}+q_{j, t}\right)\right) q_{i, t}-\left(A_{i}-k_{i, t}-\beta k_{j, t}\right) q_{i, t}-\gamma_{i} \frac{x_{i, t}^{2}}{2}\right],
\end{aligned}
$$


subject to

$$
\begin{aligned}
k_{i, t+1} & =(1-d) k_{i, t}+x_{i, t}, \\
k_{i, 0} & =0 \\
\pi_{i, T}\left(k_{i, T}, k_{j, T}\right) & =(1+\rho)^{-T} k_{i, T}=\text { free }, \\
i, j & =1,2, i \neq j .
\end{aligned}
$$

The condition $\pi_{i, T}\left(k_{i, T}, k_{j, T}\right)=k_{i, T}=$ free represents the following endpoint assumption: by the end of the planned period both agents dispose their knowledge stocks at unit price. It is clear that $q_{i, t}=q\left(k_{i, t}, k_{j, t}\right)$, thus the output decision in these dynamic problems can be obtained in the same way as it is done in a static case. When each firm maximizes its profit function for the output level $q_{i, t}$ separately from another, the first order conditions provide the following system of equations:

$$
\left(\begin{array}{ll}
-2 & -1 \\
-1 & -2
\end{array}\right)\left(\begin{array}{l}
q_{i, t}^{*} \\
q_{j, t}^{*}
\end{array}\right)=\left(\begin{array}{l}
A_{1}-1-x_{i, t}-\beta x_{j, t} \\
A_{2}-1-x_{j, t}-\beta x_{i, t}
\end{array}\right)
$$

which gives us

$$
q_{i, t}^{*}=\frac{1}{3}\left(1-2 A_{i}+A_{j}+(2-\beta) k_{i, t}+(2 \beta-1) k_{j, t}\right), i, j=1,2, i \neq j .
$$

Thus, the first-stage problem is specified as follows:

$$
\begin{aligned}
\max _{\left\{x_{i, t}\right\}} \pi_{i}^{*}= & \pi_{i, T}\left(k_{i, T}, k_{j, T}\right)+ \\
& \sum_{t=0}^{T-1}(1+\rho)^{-t}\left[\frac{1}{9}\left(1-2 A_{i}+A_{j}+(2-\beta) k_{i, t}+(2 \beta-1) k_{j, t}\right)^{2}-\gamma_{i} \frac{x_{i, t}^{2}}{2}\right],
\end{aligned}
$$

subject to the same constraints as in the second-stage problem

This problem can be rewritten in the matrix form as a nonzero-sum discrete difference game of the linear-quadratic type with linear state interactions with the state vector $z_{t}$ and the control vector $u_{i, t}$ :

$$
\begin{aligned}
\max _{\left\{u_{i, t}\right\}} \pi_{i}^{*} & =\omega_{i, T} z_{T}+\sum_{t=0}^{T-1}\left[\frac{1}{2} z_{t}^{\prime} W_{i, t} z_{t}+\omega_{i, t}^{\prime} z_{t}+\frac{1}{2} u_{i, t}^{\prime} \Lambda_{i i, t} u_{i, t}+V_{i, t}\right], \\
z_{t} & =\left(\begin{array}{l}
k_{1, t} \\
k_{2, t}
\end{array}\right), \quad u_{i, t}=\left(x_{i, t}\right), \\
i, j & =1,2, i \neq j .
\end{aligned}
$$

subject to

$$
z_{t+1}=A z_{t}+B_{i, t} u_{i, t}+B_{j, t} u_{j, t} .
$$

The parameters of the profit maximizing problem for agent $i$ is described by 
the following set of matrices:

$$
\begin{aligned}
z_{0} & =\left(\begin{array}{l}
0 \\
0
\end{array}\right), \\
A & =\left(\begin{array}{cc}
1-d & 0 \\
0 & 1-d
\end{array}\right), \\
\Lambda_{i i, t} & =-(1+\rho)^{-t} \gamma_{i}, \\
V_{i, t} & =\frac{1}{9}(1+\rho)^{-t}\left(1-2 A_{i}+A_{j}\right)^{2}, \\
t & \in[0, T], \quad i, j=1,2, \quad i \neq j .
\end{aligned}
$$

The agent-specific parameter matrices are:

$$
\begin{aligned}
B_{1, t} & =1, \quad B_{2, t}=1 \\
W_{1, t} & =-\frac{2}{9}(1+\rho)^{-t}\left(\begin{array}{cc}
(2-\beta)^{2} & (2-\beta)(2 \beta-1) \\
(2-\beta)(2 \beta-1) & (2 \beta-1)^{2}
\end{array}\right), \\
\omega_{1, t} & =\frac{2}{9}(1+\rho)^{-t}\left(1-2 A_{1}+A_{2}\right)\left(\begin{array}{c}
2-\beta \\
2 \beta-1
\end{array}\right), \\
W_{2, t} & =-\frac{2}{9}(1+\rho)^{-t}\left(\begin{array}{cc}
(2 \beta-1)^{2} & (2-\beta)(2 \beta-1) \\
(2-\beta)(2 \beta-1) & (2-\beta)^{2}
\end{array}\right), \\
\omega_{2, t} & =\frac{2}{9}(1+\rho)^{-t}\left(1-2 A_{2}+A_{1}\right)\left(\begin{array}{c}
2 \beta-1 \\
2-\beta
\end{array}\right), \\
\omega_{1, T} & =(1+\rho)^{-t}\left(\begin{array}{l}
1 \\
0
\end{array}\right), \quad \omega_{2, T}=(1+\rho)^{-T}\left(\begin{array}{l}
0 \\
1
\end{array}\right) .
\end{aligned}
$$

The profit functions of two agents interact only via the state equation, thus the optimal Nash feedback strategy of agent $i$ comes from the coupled problem defined in the following proposition. This problem is optimized using a dynamic programming technique.

Proposition 1 Consider a nonzero-sum discrete difference game of the linearquadratic type with linear state interactions. The game's state dynamics is given by:

$$
z_{t+1}=A z_{t}+B_{i, t} u_{i, t}+B_{j, t} u_{j, t} .
$$

The payoff of firm $i$ is:

$$
\begin{aligned}
\pi_{i} & =\omega_{i, T} z_{T}+\sum_{t=0}^{T-1}\left[\frac{1}{2} z_{t}^{\prime} W_{i, t} z_{t}+\omega_{i, t}^{\prime} z_{t}+\frac{1}{2} u_{i, t}^{\prime} \Lambda_{i i, t} u_{i, t}+V_{i, t}\right], \\
i, j & =1,2, \quad i \neq j .
\end{aligned}
$$

Then there exist an optimal feedback solution:

$$
u_{t}=G_{t} z_{t}+g_{t},
$$


where feedback rules are given by:

$$
\begin{aligned}
G_{t} & =\left(\begin{array}{cc}
\Theta_{i i, t} & \Theta_{i j, t} \\
\tilde{\Theta}_{j i, t} & \tilde{\Theta}_{j j, t}
\end{array}\right)^{-1}\left(\begin{array}{c}
\Psi_{i, t}^{\prime} \\
\tilde{\Psi}_{j, t}^{\prime}
\end{array}\right), \\
g_{t} & =\left(\begin{array}{cc}
\Theta_{i i, t} & \Theta_{i j, t} \\
\tilde{\Theta}_{j i, t} & \tilde{\Theta}_{j j, t}
\end{array}\right)^{-1}\left(\begin{array}{c}
\theta_{i, t} \\
\tilde{\theta}_{j, t}
\end{array}\right) .
\end{aligned}
$$

The transformation matrices are generated by:

$$
\begin{gathered}
K_{i, t}=A_{t}^{\prime} K_{i, t+1} A_{t}+W_{i, t}+G_{t}^{\prime}\left(\begin{array}{cc}
\Theta_{i i, t} & \Theta_{i j, t} \\
\Theta_{i j, t} & \Theta_{j j, t}
\end{array}\right) G_{t}+2\left(\begin{array}{c}
\Psi_{i, t} \\
\Psi_{j, t}
\end{array}\right)^{\prime} G_{t}, \\
p_{i, t}=A_{t}^{\prime} p_{i, t+1}+\omega_{i, t}+\left(\begin{array}{c}
\Psi_{i, t} \\
\Psi_{j, t}
\end{array}\right)^{\prime} g_{t}+G_{t}^{\prime}\left(\begin{array}{cc}
\Theta_{i i, t} & \Theta_{i j, t} \\
\Theta_{i j, t} & \Theta_{j j, t}
\end{array}\right) g_{t}+G_{t}^{\prime}\left(\begin{array}{c}
\theta_{i, t} \\
\theta_{j, t}
\end{array}\right),
\end{gathered}
$$

and

$$
\begin{gathered}
K_{j, t}=A_{t}^{\prime} K_{j, t+1} A_{t}+W_{j, t}+G_{t}^{\prime}\left(\begin{array}{cc}
\tilde{\Theta}_{i i, t} & \tilde{\Theta}_{j i, t} \\
\tilde{\Theta}_{j i, t} & \tilde{\Theta}_{j j, t}
\end{array}\right) G_{t}+2\left(\begin{array}{c}
\tilde{\Psi}_{i, t} \\
\tilde{\Psi}_{j, t}
\end{array}\right)^{\prime} G_{t}, \\
p_{j, t}=A_{t}^{\prime} p_{j, t+1}+\omega_{j, t}+\left(\begin{array}{c}
\tilde{\Psi}_{i, t} \\
\tilde{\Psi}_{j, t}
\end{array}\right)^{\prime} g_{t}+G_{t}^{\prime}\left(\begin{array}{cc}
\tilde{\Theta}_{i i, t} & \tilde{\Theta}_{j i, t} \\
\tilde{\Theta}_{j i, t} & \tilde{\Theta}_{j j, t}
\end{array}\right) g_{t}+G_{t}^{\prime}\left(\begin{array}{c}
\tilde{\theta}_{i, t} \\
\tilde{\theta}_{j, t}
\end{array}\right),
\end{gathered}
$$

where

$$
\begin{aligned}
\Psi_{i, t} & =A_{t}^{\prime} K_{i, t+1} B_{i, t}, \\
\Psi_{j, t} & =A_{t}^{\prime} K_{i, t+1} B_{j, t}, \\
\Theta_{i i, t} & =B_{i, t}^{\prime} K_{i, t+1} B_{i, t}+\Lambda_{i i, t}, \\
\Theta_{i j, t} & =B_{i, t}^{\prime} K_{i, t+1} B_{j, t}, \\
\Theta_{j j, t} & =B_{j, t}^{\prime} K_{i, t+1} B_{j, t}, \\
\theta_{i, t}^{\prime} & =B_{i, t}^{\prime} p_{i, t+1}, \\
\theta_{j, t}^{\prime} & =B_{j, t}^{\prime} p_{i, t+1},
\end{aligned}
$$

and

$$
\begin{aligned}
\tilde{\Psi}_{i, t} & =A_{t}^{\prime} K_{j, t+1} B_{i, t}, \\
\tilde{\Psi}_{j, t} & =A_{t}^{\prime} K_{j, t+1} B_{j, t}, \\
\tilde{\Theta}_{i i, t} & =B_{i, t}^{\prime} K_{j, t+1} B_{i, t}, \\
\tilde{\Theta}_{j i, t} & =B_{j, t}^{\prime} K_{j, t+1} B_{i, t}, \\
\tilde{\Theta}_{j j, t} & =B_{j, t}^{\prime} K_{j, t+1} B_{j, t}+\Lambda_{j j, t}, \\
\tilde{\theta}_{i, t}^{\prime} & =B_{i, t}^{\prime} p_{j, t+1}, \\
\tilde{\theta}_{j, t}^{\prime} & =B_{j, t}^{\prime} p_{j, t+1} .
\end{aligned}
$$


Proof. See Appendix.

We solve this coupled problem employing a solution technique inspired by Kendrick (1987) for a common quadratic-linear optimal control problem. We decentralize the Kendrick's procedure to include the interactions between two agents' state and control variables (see Appendix). The problem is solved numerically by integrating Ricatti equations. As a result we receive a sequence of optimal R\&D investments $\left\{x_{i, t}^{*}\right\}$ and production volumes $\left\{q_{i, t}^{*}\right\}$, corresponding to the knowledge capital trajectory $\left\{k_{i, t}^{*}\right\}, t \in[0, T-1], i=1,2$. Maximization of the coupled problem stated above requires matrix $W_{i, t}$ is non-positively definite for any $t \in[0, T-1], i=1,2$.

\subsubsection{Technology Sharing Competition (TSC).}

Here we pick up an idea of Petit and Tolwinski (1999) about possibility of sharing technological information between firms without making any additional cooperative agreements. Such an arrangement occurs when two firms agree to fully share their technological knowledge while still competing in production. It represents a special case of the non-cooperative duopoly in the situation, when both firms completely internalize knowledge spillovers, thus assuming $\beta=1$. Being different only in the value of one parameter, the game of technology sharing competition is solved in a same manner as the problem of non-cooperative duopoly.

\subsection{R\&D Cooperating and Competitive Production Duopoly $(\mathrm{C}, \mathrm{NC})$}

In this case we have agents, which decided to cooperate in R\&D (i.e. to invest in research in such a way that the joint profit function is maximized) and still compete in production. As companies agree to cooperate in research, and they are able to set $\hat{\beta}>\beta$ implying that the members of consortium share their knowledge more than the natural rate of knowledge spillovers, but not yet completely. This arrangement is described as a Research Joint Venture (RJV) with partially internalized spillovers

As in the non-cooperative duopoly, the second-stage game at a given moment $t$ yields the following optimal production levels:

$$
\begin{aligned}
\hat{q}_{i, t} & =\frac{1}{3}\left(1-2 A_{i}+A_{j}+(2-\hat{\beta}) k_{i, t}+(2 \hat{\beta}-1) k_{j, t}\right), \\
\text { for } \forall t & \in[0, T-1], \quad i, j=1,2, i \neq j .
\end{aligned}
$$

In the first stage the firms maximize the joint profit function is specified as follows:

$$
\begin{aligned}
\max _{\left\{x_{t}\right\}} \hat{\pi}= & \pi_{T}\left(k_{1, T}, k_{2, T}\right)+\sum_{t=0}^{T-1}(1+\rho)^{-t}\left[\frac{1}{9}\left(1-2 A_{1}+A_{2}+(2-\hat{\beta}) k_{1, t}+(2 \hat{\beta}-1) k_{2, t}\right)^{2}+\right. \\
& \left.\frac{1}{9}\left(1-2 A_{2}+A_{1}+(2-\hat{\beta}) k_{2, t}+(2 \hat{\beta}-1) k_{1, t}\right)^{2}-\gamma_{1} \frac{x_{1, t}^{2}}{2}-\gamma_{2} \frac{x_{2, t}^{2}}{2}\right],
\end{aligned}
$$


subject to

$$
\begin{aligned}
k_{i, t+1} & =(1-d) k_{i, t}+x_{i, t}, \\
k_{i, 0} & =0 \\
\pi_{T}\left(k_{1, T}, k_{2, T}\right) & =(1+\rho)^{-T}\left(k_{1, T}+k_{2, T}\right)=\text { free }, \\
i, j & =1,2, i \neq j .
\end{aligned}
$$

In matrix notation the problem is specified as:

$$
\max _{\left\{u_{i, t}\right\}} \hat{\pi}=\omega_{T} z_{T}+\sum_{t=0}^{T-1}\left[\frac{1}{2} z_{t}^{\prime} W_{t} z_{t}+\omega_{t}^{\prime} z_{t}+\frac{1}{2} u_{t}^{\prime} \Lambda_{t} u_{t}+V_{t}\right],
$$

subject to

$$
z_{t+1}=A z_{t}+B_{t} u_{t}
$$

with parameters matrices:

$$
\begin{aligned}
z_{t} & =\left(\begin{array}{l}
k_{1, t} \\
k_{2, t}
\end{array}\right), \quad u_{t}=\left(\begin{array}{l}
x_{1, t} \\
x_{2, t}
\end{array}\right), \quad u_{i, t}=\left(x_{i, t}\right), \\
z_{0} & =\left(\begin{array}{l}
0 \\
0
\end{array}\right), \quad \omega_{T}=(1+\rho)^{-T}\left(\begin{array}{l}
1 \\
1
\end{array}\right), \\
A & =\left(\begin{array}{cc}
1-d & 0 \\
0 & 1-d
\end{array}\right), \quad B_{t}=\left(\begin{array}{ll}
1 & 0 \\
0 & 1
\end{array}\right), \\
W_{t} & =-\frac{2}{9}(1+\rho)^{-t}\left(\begin{array}{cc}
(2-\hat{\beta})^{2}+(2 \hat{\beta}-1)^{2} & 2(2-\hat{\beta})(2 \hat{\beta}-1) \\
2(2-\hat{\beta})(2 \hat{\beta}-1) & (2-\hat{\beta})^{2}+(2 \hat{\beta}-1)^{2}
\end{array}\right), \\
\omega_{t} & =\frac{2}{9}(1+\rho)^{-t}\left(\begin{array}{c}
1+\hat{\beta})+(4 \hat{\beta}-5) A_{1}+(4-5 \hat{\beta}) A_{2} \\
(1+\hat{\beta})+(4-5 \hat{\beta}) A_{1}+(4 \hat{\beta}-5) A_{2}
\end{array}\right), \\
\Lambda_{t} & =-(1+\rho)^{-t}\left(\begin{array}{cc}
-\gamma_{1} & 0 \\
0 & -\gamma_{2}
\end{array}\right), \\
V_{t} & =\frac{1}{9}(1+\rho)^{-t}\left[\left(1-2 A_{1}+A_{2}\right)^{2}+\left(1-2 A_{2}+A_{1}\right)^{2}\right], \\
\omega_{T} & =(1+\rho)^{-t}\left(\begin{array}{l}
1 \\
1
\end{array}\right), \\
t & \in[0, T] .
\end{aligned}
$$

This problem is a case of linear-quadratic optimization problem. Results are the optimal values of $\left\{\hat{x}_{i, t}\right\},\left\{\hat{q}_{i, t}\right\},\left\{\hat{k}_{i, t}\right\}, t \in[0, T-1], i=1,2$. And the maximization requires $W_{t} \leq 0, t \in[0, T-1], i=1,2$. Solution of this problem follows the procedure given in Kendrick (1987, p.115) for a common quadraticlinear optimal control problem. Correspondingly, for this type of problems we formulate the following proposition.

Proposition 2 Consider a discrete optimization problem of the linear-quadratic type with linear state. The problem's state dynamics is given by:

$$
z_{t+1}=A z_{t}+B_{i, t} u_{i, t}+B_{j, t} u_{j, t} .
$$


The payoff of the agent is:

$$
\pi=\omega_{T} z_{T}+\sum_{t=0}^{T-1}\left[\frac{1}{2} z_{t}^{\prime} W_{i, t} z_{t}+\omega_{t}^{\prime} z_{t}+\frac{1}{2} u_{t}^{\prime} \Lambda_{t} u_{t}+V_{t}\right]
$$

Then there exist an optimal feed-back solution:

$$
u_{i, t}^{*}=G_{t} z_{t}+g_{t},
$$

where feedback rules are given by:

$$
\begin{aligned}
G_{t} & =-\left(\Theta_{t}\right)^{-1} \Psi_{t}^{\prime}, \\
g_{t} & =-\left(\Theta_{t}\right)^{-1} \theta_{t} .
\end{aligned}
$$

The transformation matrices are generated by:

$$
\begin{gathered}
K_{i, t}=A_{t}^{\prime} K_{t+1} A_{t}+W_{t}+G_{t}^{\prime} \Theta_{t} G_{t}+2 \Psi_{t} G_{t}, \\
p_{i, t}=A_{t}^{\prime} p_{i, t+1}+\omega_{i, t}+\left(\Psi_{t}+G_{t}^{\prime} \Theta_{t}^{\prime}\right) g_{t}+G_{t}^{\prime} \theta_{t} .
\end{gathered}
$$

where

$$
\begin{aligned}
\Psi_{t} & =A_{t}^{\prime} K_{t+1} B_{t}, \\
\Theta_{t} & =B_{t}^{\prime} K_{t+1} B_{t}+\Lambda_{t}, \\
\theta_{t}^{\prime} & =B_{t}^{\prime} p_{t+1} .
\end{aligned}
$$

Proof. See Kendrick (1987, pp.115-119).

\subsection{R\&D and Production Cooperating Duopoly/Monopoly $(\mathrm{C}, \mathrm{C})$}

In this mode the duopoly actually ceases to exist and the consortium's problem transforms into a one-firm optimal control problem:

$$
\begin{aligned}
\max _{\left\{q_{i, t}, x_{i, t}\right\}} \pi^{* *}= & \pi_{T}\left(k_{1, T}, k_{2, T}\right)+ \\
& \sum_{t=0}^{T-1}(1+\rho)^{-t}\left[\left(1-q_{1, t}-q_{2, t}\right) q_{1, t}-\left(A_{1}-k_{1, t}-k_{2, t}\right) q_{1, t}-\gamma_{1} \frac{x_{1, t}^{2}}{2}+\right. \\
& \left.\left(1-q_{1, t}-q_{2, t}\right) q_{2, t}-\left(A_{2}-k_{1, t}-k_{2, t}\right) q_{2, t}-\gamma_{2} \frac{x_{2, t}^{2}}{2}\right]
\end{aligned}
$$

subject to

$$
\begin{aligned}
k_{i, t+1} & =(1-d) k_{i, t}+x_{i, t}, \\
k_{i, 0} & =0, \\
\pi_{T}\left(k_{1, T}, k_{2, T}\right) & =(1+\rho)^{-T}\left(k_{1, T}+k_{2, T}\right)=\text { free }, \\
i, j & =1,2, i \neq j .
\end{aligned}
$$


Now there is one important moment to draw our attention to. Unlike in the models with symmetric agents (A\&J(88), Petit and Tolwinski (1999), Kline (2000), Salant and Shaffer (1998), Suzumura (1992)), solution of the monopolistic collusion of asymmetric agents does not come down to the choice of one common level of output and R\&D investment, which is equally shared by two firms. The players in our model have different research and production capacities, therefore optimization requires solution for two separate optimal levels of the output and R\&D corresponding to each firm.

If we solve this problem for the optimal outputs, it turns out that it does not provide a unique solution. The First Order Conditions (FOC) matrix, corresponding to this problem is not negatively definite and thus we must turn to the corner solutions. It is possible to show that in a case when one firm is more efficient in both research and production, there is one solution, which dominates above all the other ones for any given combination of the model parameters. This solution corresponds to the situation, where only a more efficient firm (agent 1 in our case) produces the output, but both firms carry out the R\&D: $q_{i, t}^{* *} \neq 0, \quad q_{j, t}^{* *}=0, \quad x_{i, t}^{* *}, x_{j, t}^{* *} \neq 0, \quad t=[0, T], \quad i, j=1,2, \quad i \neq j$.

Now, if consider the monopolistic collusion problem with only firm $i$ producing:we maximize the following objective function:

$$
\begin{aligned}
\max _{\left\{q_{i, t}, x_{i, t}\right\}} \pi_{t}= & \pi_{T}\left(k_{1, T}, k_{2, T}\right) \sum_{t=0}^{T-1}(1+\rho)^{-t}\left[\left(1-q_{i, t}\right) q_{i, t}-\right. \\
& \left.\left(A_{i}-k_{i, t}-k_{j, t}\right) q_{i, t}-\gamma_{i} \frac{x_{i, t}^{2}}{2}-\gamma_{j} \frac{x_{j, t}^{2}}{2}\right] .
\end{aligned}
$$

Production decision rule in this case is:

$$
q_{i, t}^{* *}=\frac{1}{2}\left(1-A_{i}+k_{i, t}+k_{j, t}\right), \quad q_{j, t}^{* *}=0, \quad t \in[0, T-1], \quad i, j=1,2, \quad i \neq j .
$$

After we substitute this rule into the initial second-stage problem, we get a single-stage problem with objective function:

$\max _{\left\{x_{t}\right\}} \pi_{t}^{* *}=\pi_{T}\left(k_{1 T}, k_{2 T}\right)+\sum_{t=0}^{T-1}(1+\rho)^{-t}\left[\frac{1}{4}\left(1-A_{i}+k_{i, t}+k_{j, t}\right)^{2}-\gamma_{i} \frac{x_{i, t}^{2}}{2}-\gamma_{j} \frac{x_{j, t}^{2}}{2}\right]$,

subject to the constraints given above.

The problem above is equivalent to:

$$
\max _{\left\{u_{t}\right\}} \pi_{t}^{* *}=\omega_{T} z_{T}+\sum_{t=0}^{T-1}\left[\frac{1}{2} z_{t}^{\prime} W_{t} z_{t}+\omega_{t}^{\prime} z_{t}+\frac{1}{2} u_{t}^{\prime} \Lambda_{t} u_{t}+V_{t}\right],
$$

subject to

$$
z_{t+1}=A z_{t}+B_{t} u_{t}
$$


The corresponding parameters matrices are given as:

$$
\begin{aligned}
z_{t} & =\left(\begin{array}{l}
k_{1 t} \\
k_{2 t}
\end{array}\right), u_{t}=\left(\begin{array}{l}
x_{1 t} \\
x_{2 t}
\end{array}\right), \\
z_{0} & =\left(\begin{array}{l}
0 \\
0
\end{array}\right), \omega_{T}=(1+\rho)^{-T}\left(\begin{array}{l}
1 \\
1
\end{array}\right) \\
A & =\left(\begin{array}{cc}
1-d & 0 \\
0 & 1-d
\end{array}\right), B_{t}=\left(\begin{array}{ll}
1 & 0 \\
0 & 1
\end{array}\right), \\
W_{t} & =-\frac{1}{2}(1+\rho)^{-t}\left(\begin{array}{cc}
1 & 1 \\
1 & 1
\end{array}\right) \\
w_{t} & =\frac{1}{2}(1+\rho)^{-t}\left(1-A_{i}\right)\left(\begin{array}{l}
1 \\
1
\end{array}\right) \\
\Lambda_{t} & =-(1+\rho)^{-t}\left(\begin{array}{cc}
-\gamma_{1} & 0 \\
0 & -\gamma_{2}
\end{array}\right) \\
V_{t} & =\frac{1}{4}(1+\rho)^{-t}\left(1-A_{i}\right)^{2} .
\end{aligned}
$$

The numerical solution of this problem follows the same steps as in the R\&D cooperation with competitive production mode and is represented by $\left\{x_{i, t}^{* *}\right\}$, $\left\{q_{i, t}^{* *}\right\}$, and $\left\{k_{i, t}^{* *}\right\}, \quad t \in[0, T-1], \quad i=1,2$.

\section{Numerical simulations}

In order to illustrate the solutions of this model we provide results of a numerical simulation. We have calibrated parameters of the model using the non-negative price and marginal cost conditions together with limitations imposed by the second order conditions in problems corresponding to different cooperation/competition modes:

i) The asymmetry between agents is assumed to be full, i.e. one agent has total advantage over another.

ii) The less efficient firms has $10 \%$ higher marginal cost of production and per-unit marginal cost of research than a more efficient one $\left(A_{1}=0.5, \quad A_{2}=\right.$ 0.55 and $\left.\gamma_{1}=135, \quad \gamma_{2}=148.5\right)$.

iii) In the $R \& D$ cooperation mode the firms decide to exchange their knowledge completely $(\hat{\beta}=1)$.

iii) The agents are given 150 periods to plan their strategies $(t \in[0,150])$.

iv) The knowledge capital depreciation rate is $d=0.1$.

v) The future profit discount rate is $\rho=0.05$.

\subsection{Time Paths of the Control and State Variables}

First we analyze the dynamics of control and state variable in the model. Figure 1 shows that two asymmetric agents invest in R\&D and produce asymmetrically, the fact first observed in the static model of Salant and Shaffer (1998). The 

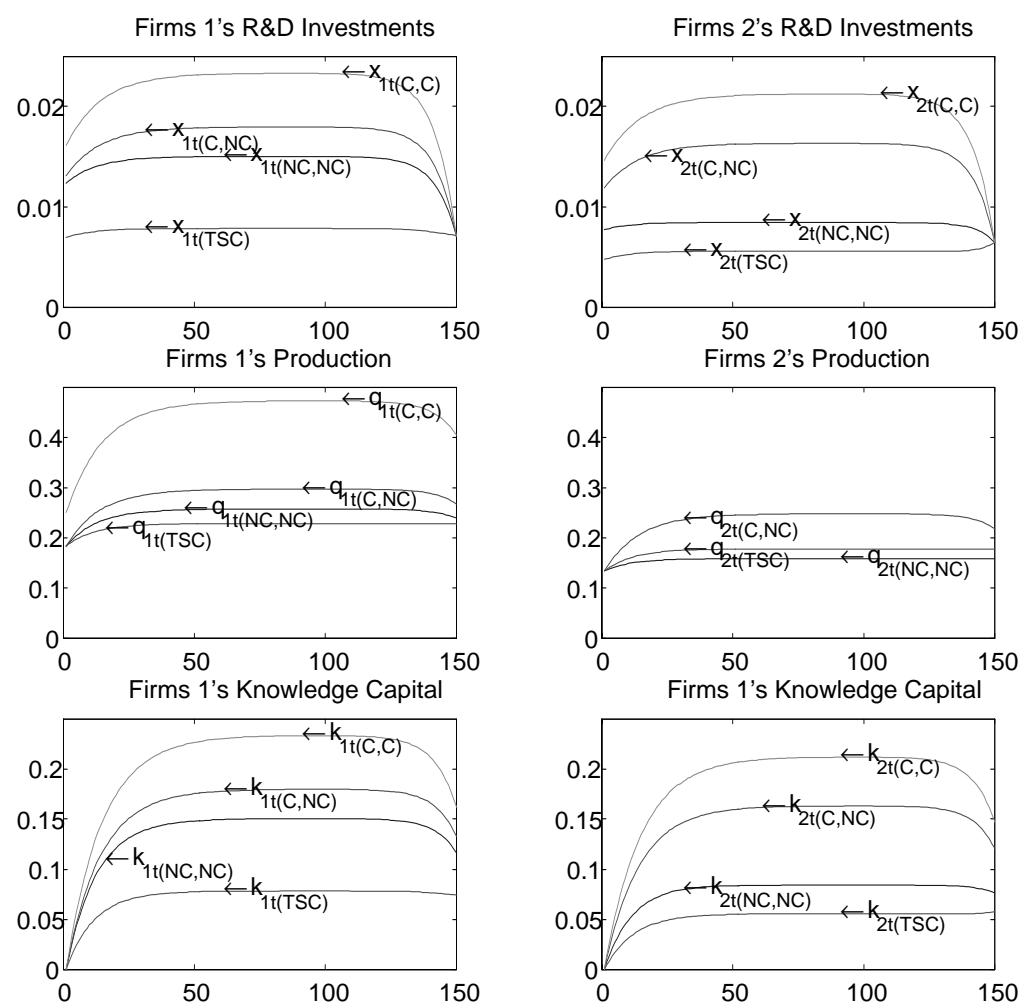

Figure 1: Firms' individual controls and states in different cooperation modes $(\beta=0.25)$ 
more efficient firm invests in R\&D and produces more than the less efficient one. The firms' $R \& D$ investment trajectories exhibit several special features:

i) in the beginning of the planning period the $R \& D$ investment increases over time at a decreasing rate;

ii) at the certain moment in time the $R \& D$ investment rate stabilizes and remains constant;

ii) closer to the end of game the R\&D investment drops dramatically.

Other two variables, output and the knowledge capital stock experience the similar three-stage behavior.

The knowledge capital stock of two agents grows until at a certain moment in time the rate of $R \& D$ investment becomes lower than the knowledge capital depreciation rate, after which it starts to decrease. In the beginning firms invest heavily in $R \& D$ in order to build up the cost decreasing knowledge capital stock. But knowing that in the end they will have to dispose their knowledge capital, the agents gradually shrink their research programs, preparing for closure and economizing on R\&D costs. The closer they get to the end, the faster decrease their R\&D expenditures. On the other hand, the output volumes do not fluctuate as much as R\&D expenditures, because the production cost gains rely on already substantial levels of accumulated knowledge capital.

Doraszelski (2003) points out that firms decrease their R\&D investments as knowledge stock grows. Out results show that firm's knowledge capital and its R\&D investment follow similar paths, therefore the pure knowledge effect is not negative as observed in the Doraszelski's model, but positive. Firms in our study decrease their R\&D efforts as the game approaches its end, but this decrease is accompanied by the corresponding decrease in their knowledge capital.

Comparing the firms' R\&D investment dynamics in different cooperation/competition modes we observe that the firm's R\&D efforts are negatively affected by the knowledge spillovers rate in the fully competitive mode as we observe firms' R\&D investments with not internalized spillovers (NC,NC mode) to be higher than when these spillovers are internalized (TSC mode). If we analyze, how much do firms invest in cooperative modes compared to the fully competitive one, we find that firms' R\&D investment is higher when the an RJV is created. This finding is opposite to the result of Reinganum (1981) stating that "Nash rivals invest in $\mathrm{R} \& \mathrm{D}$ at a uniformly higher rate than do cooperative (tacitly collusive) rivals."

Here we observe that in the $R \& D$ cooperative mode spillovers are not only internalized, but an additional cooperation is made, that allows firms to accumulate and utilize their knowledge more efficiently. We discuss this fact a bit later below.

\subsection{Markets and the Firms' Profit Functions}

The market dynamics corresponding to the firms' strategies is shown in Figure 2. The market exhibits a three-stage time path. In the beginning the prices drop considerably in all modes. Then the situation stabilizes and the prices remain 


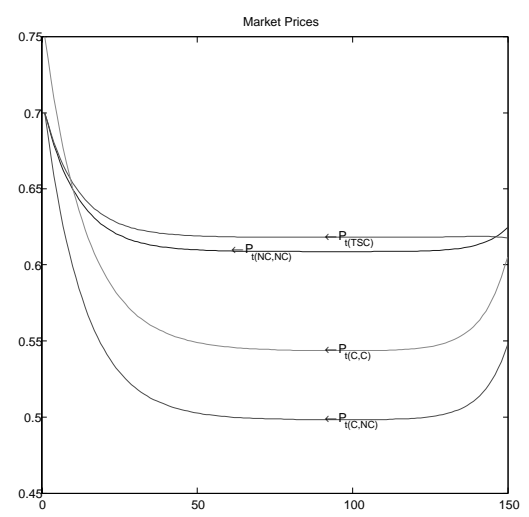

Figure 2: The market price in different competition/cooperation modes $(\beta=$ $0.25)$

flat. As firms approach the final date, the prices climb back. Therefore we can talk about a certain market saturation point, which, once reached, does not allow the firms to expand their production and, therefore, their R\&D programs. And close to termination the firms wrap their production up, making the prices increase ${ }^{1}$.

Here we would like to point at one surprising result. At the market saturation stage, the prices in monopoly mode are actually lower than the prices in full competition. This result is opposite to the findings of Petit and Tolwinski (1999), who argue that monopoly results in the highest prices in the market. In general, it could be expected that creation of a monopoly will result in a least efficient market with highest prices.

In order to investigate this difference we have changed the R\&D cost function specification from

$$
C_{i}^{r}\left(x_{i, t}\right)=\gamma_{i} \frac{x_{i, t}^{2}}{2}
$$

to

$$
C_{i}^{r}\left(x_{i, t}\right)=x_{i, t}+\gamma_{i} \frac{x_{i, t}^{2}}{2}, \quad i=1,2,
$$

which is the same as in Petit and Tolwinski (1999). We simulated our model for the case of two symmetric firms. Under this new assumption the simulation produced results consistent with the Petit and Tolwinski's (1999) finding, i.e. prices in the monopolistic collusion mode are the highest.

We also simulated a symmetric case of our model in order to isolate the effect of the R\&D cost function specification change. Results show, that monopolistic collusion of two symmetric firms gives the monopoly price below that of full

\footnotetext{
${ }^{1}$ Such situation occurs only if there is no adequate substitute introduced for the phasing-out technology.
} 
competition in the middle part of the game's duration. Therefore, we obtain the results consistent with Petit and Tolwinski's only if we use their R\&D cost function specification.

A study of the literature has shown that the original A\&J (88) R\&D cost specification is much more widely used than the version adopted by Petit and Tolwinski (1999) (and also by Vonortas (1994)). Therefore, considering the our results, we argue, that a special attention should be paid to investigating the functional form of $R \& D$ cost function. Existence of a linear component in R\&D cost is not important for static models, but surely makes the difference when the model is dynamic.

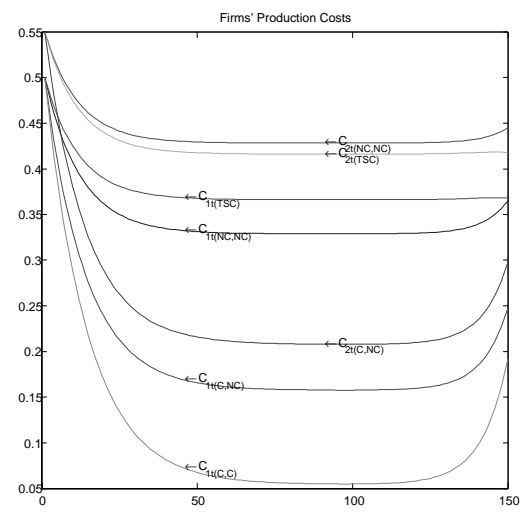

Figure 3: Firms' production costs dynamics in different compatition/cooperation modes $(\beta=0.25)$

The fact that knowledge capital in our model increases and then decreases implies that production cost of the two firms decreases only in the beginning of the game and even starts to grow close to the game termination moment. Closer to the end the benefit from each consecutive innovation lasts shorter and shorter, therefore decreasing the incentive to invest in R\&D. At a certain moment in time the rate of innovation becomes lower than the knowledge depreciation rate, which implies that the firm wraps up its $R \& D$ program and prepares for termination.

It can be seen in Figure 3 that the firms' production costs remain on fairly high levels during the game. Firms in full competition mode produce with the highest production costs, while in the $\mathrm{R} \& \mathrm{D}$ cooperation and in the monopolistic mode they reach much lower marginal production cost levels. The same holds when comparing it to the technology sharing competition mode.

\subsection{Firms' Profit Functions and Welfare Implications}

Figure 4 presents trajectories of the firms' individual profit functions. In the beginning of the game the firms experience a substantial rise in current profits 

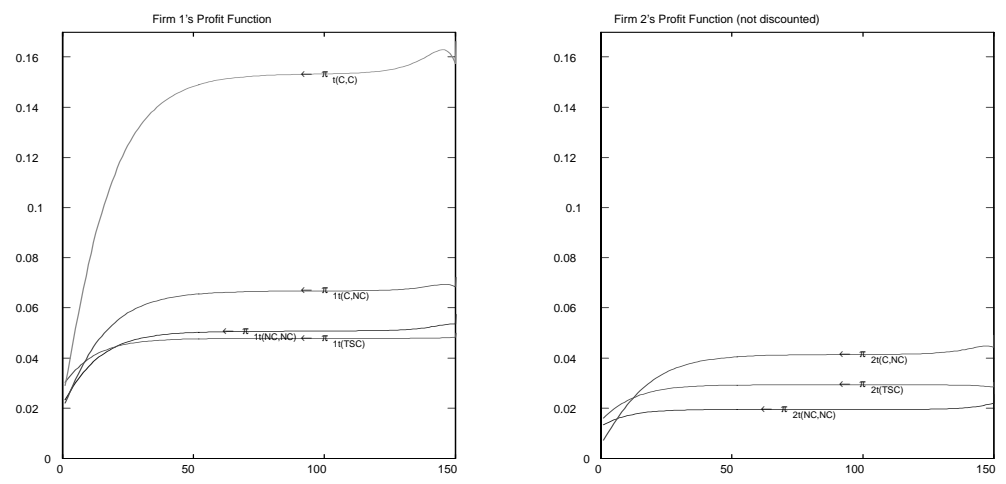

Figure 4: Firms' individual (current) profit functions in different competition/cooperation modes $(\beta=0.25)$

as a result of their innovation activities. But this growth takes place at a decreasing rate and later in the game the profits stabilize on an almost constant level. Close to the termination date the profit dynamics changes as the firms adjust their R\&D investments and outputs in preparation for the end.
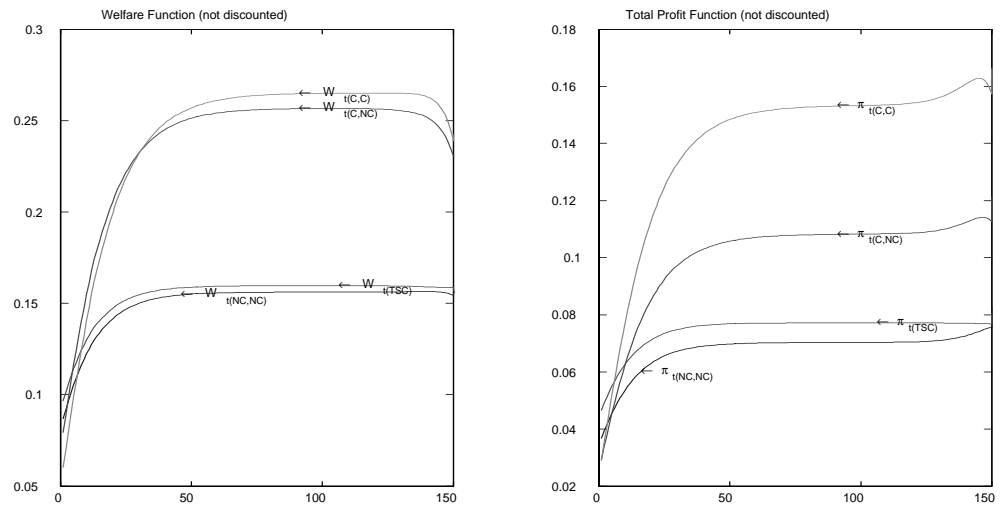

Figure 5: Total welfare and industry's profit functions in different competition/cooperation modes $(\beta=0.25)$

In Figure 5 we present the dynamics of total welfare and the total industry's profits. Table 1 gives the net present value (NPV) of the total accumulated profits and welfare obtained by the social planner during the whole duration of the game. A surprising result is that the monopoly provides higher welfare than the fully competitive duopoly. But the most desirable market structure from the social planner's point of view is the $R \& D$ cooperation with production 
competition. Firms themselves would have preferred to create a monopolistic coalition, but if it is assumed that an effective anti-trust legislation is installed in the market, the RJV will be the optimal firms' strategy and it will be socially preferred. The technology sharing competition is better than the fully noncooperative mode, but is still inferior to creation of an RJV from both firms' and social planner's points of view.

\begin{tabular}{l||l|l} 
Mode & NPV of Industry's Profit & NPV of Total Welfare \\
\hline \hline (NC,NC) & 1.1964 & 2.7076 \\
(TSC) & 1.3745 & 2.8459 \\
(C,NC) & 1.5286 & 3.7264 \\
(C,C) & 1.9892 & 3.5477
\end{tabular}

Table 1. The market profit compared to welfare in different competition/cooperation modes $(\beta=0.25)$

Provided that the firms can choose only from production-competitive modes, their decisions can not be inferred from just looking at the illustration (see Figure 4). In the beginning of the planning period the competitive profits of the firms are higher than the profits obtained when the firms decide to cooperate in $R \& D$. At the end of the game the situation is different. We also should take into account the influence of discounting. Therefore, below we examine the NPV of accumulated individual profits for both firms. Table 2 presents the corresponding results, accompanied by the plots of discounted values of the firms' individual profits in Figure.6.

\begin{tabular}{l||l|l|} 
Mode & NPV of Firm 1's Profit & NPV of Firm 2's Profit \\
\hline \hline (NC,NC) & 0.8298 & 0.3665 \\
(TSC) & 0.8651 & 0.5094 \\
(C,NC) & 0.9849 & 0.5436 \\
\hline
\end{tabular}

Table 2. The individual profits of firms in production competitive modes ( $\beta=0.25,10 \%$ level of asymmetry).

Both firms obtain higher profit when engaging in $R \& D$ cooperation. The higher profits in the beginning of the planning period can be explained by the fact that in full competition firms invest much less in $R \& D$, therefore keep their costs lower. But in the R\&D cooperation mode firms accumulate knowledge capital faster, so that they obtain a greater production cost reduction, which in the end results in higher total profits. A faster pace of knowledge accumulation in the beginning of the game translates into higher (and less discounted) production cost benefits. Therefore, the firms prefer the less competitive modes to the more competitive one. 

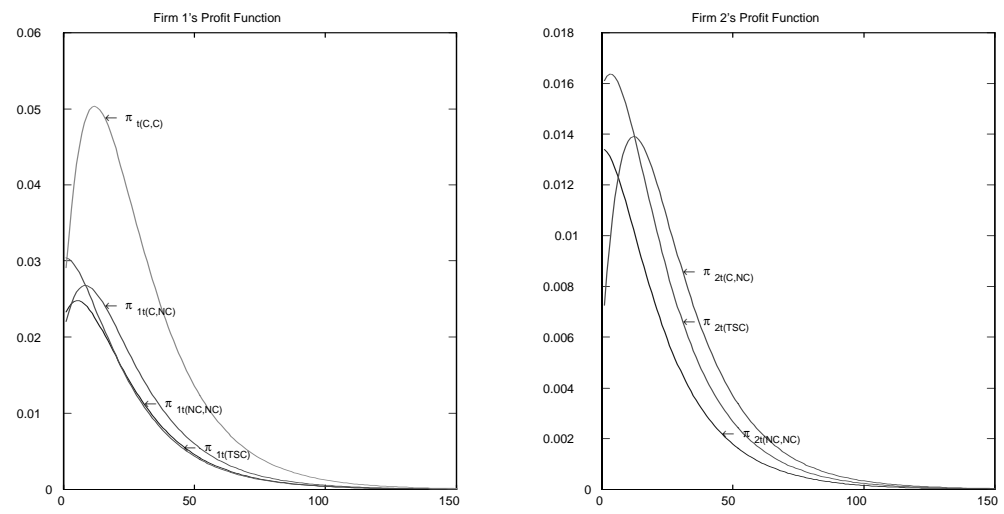

Figure 6: Firms' individual (discounted) profits in different cooperation/competition modes $(\beta=0.25)$

\section{The Effect of the Cooperative Knowledge Ex- change Level}

Let us now consider the cases when two firms create a research joint venture with an arbitrary degree of knowledge exchange. We simulate two different scenarios. First, we compare different degrees of $R \& D$ cooperation to the situation when the initial degree of knowledge spillovers is 0 (no knowledge spillovers). Secondly we make the same comparison when the initial degree of knowledge spillovers is 0.5 .

Figure 7 illustrates firms' individual total profits obtained for different degrees of $R \& D$ cooperation if initially no knowledge spillovers existed. We see that the total profits of the more efficient firm (Firm 1) decrease if the degree of R\&D cooperation is low enough. Firm 2's profit, on the other hand, increases faster in the range of weaker $R \& D$ cooperation. And if we consider the optimal production competitive structure, we conclude it is more profitable for both firms to fully compete while sharing all the knowledge, than to engage in a cooperative agreement which does not allow for a substantial level of knowledge exchange (for example with $\hat{\beta}<0.6$ ).

The best strategy for both firms is to create an RJV with full knowledge exchange $(\hat{\beta}=1)$. But if for some reasons it is possible to achieve only a certain level, which is low enough (for example in areas of defense-related research), the optimal strategy is then to cooperate in $R \& D$ without any exchange of knowledge.

The picture becomes different when the initial level of spillovers is higher. Then we can see in Figure 8 that both firms will prefer to form and RJV with a highest degree of knowledge exchange possible. Therefore the optimal level of $\mathrm{R} \& \mathrm{D}$ cooperation depends on both the maximum available level of knowledge exchange and the existing initial level of knowledge spillovers. the higher is 


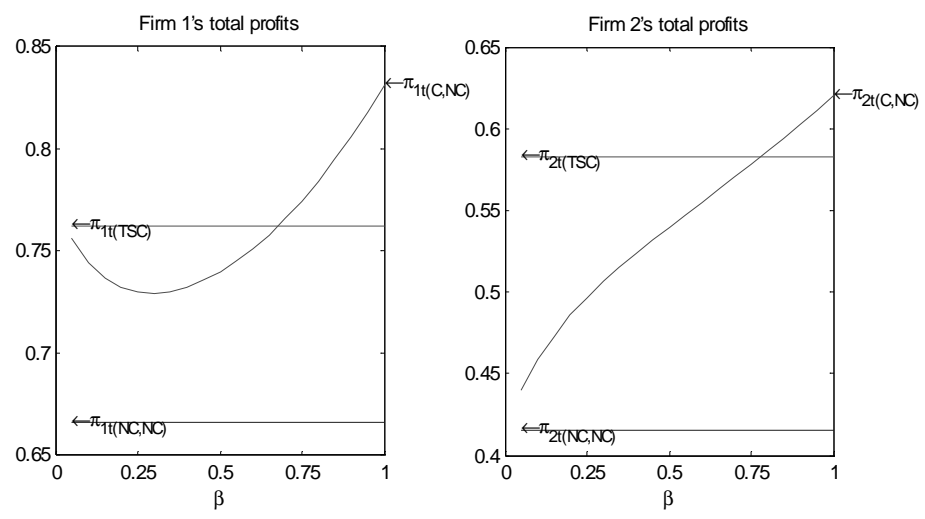

Figure 7: Firms' individual profits under different degrees of R\&D cooperation with the initial $\beta=0$.
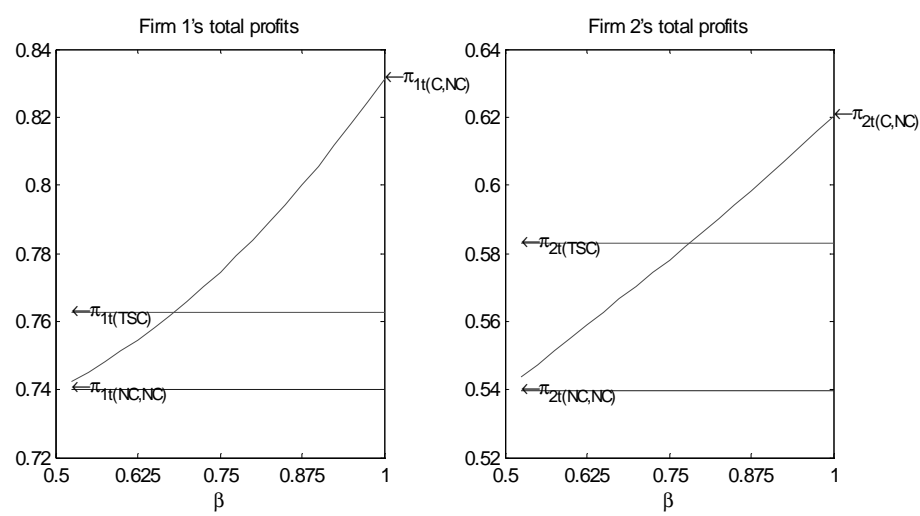

Figure 8: Firms' individual profits under different degrees of R\&D cooperation with the initial $\beta=0.5$ 
the level of knowledge spillovers. the higher is the likelihood that firms will cooperate in R\&D and fully exchange their knowledge.

\section{Conclusions}

In this paper provides a dynamic extension to the asymmetric $A \& J(88)$ model. We have simulated the behavior of agents in different R\&D cooperation modes. We have improved over the original model by assuming full internalization of knowledge spillovers in the case of $\mathrm{R} \& \mathrm{D}$ cooperation, therefore addressing the most frequent critique to this setup. The spillovers internalization in our model yields the conclusion that the firms will always prefer to either share their knowledge or to cooperate in $\mathrm{R} \& \mathrm{D}$ then to conduct research independently. If the market can possibly have only the structure with production competition, then the $\mathrm{R} \& \mathrm{D}$ cooperation mode is the one preferred by the firms and the social planner. The welfare and the firms profits can be increased also by simple agreement to share their knowledge without a deeper cooperation commitment.

If we consider the overall level of production efficiency achieved by firms as a result of innovation, we come to the conclusion that competing firms invest in innovation less than the firms working according to the cooperative agreements. Under the given model assumptions it also holds that in later periods of the game, the monopolist starts to function more effectively (with lower marginal production cost and market price) than the fully competing firms.

The dynamic model of $R \& D$ cooperation revealed a number of interesting aspects of firms' dynamic strategies, which could not be seen in the regular static setting. The model shows that in the beginning of the firms' operations, the competitive profits are higher than the profits from R\&D cooperation. The firms in the research joint venture must cope with lower profits in the beginning in order to fully enjoy the benefits of production cost reducing innovation later, which in the end results in higher current and total profits.

The model indicates that when existing knowledge spillovers are very weak, a more efficient firm can have decreasing profits from R\&D cooperation for the range of weaker cooperative arrangements (when the degree of knowledge exchange is higher than the knowledge spillovers, but still low enough) and an increasing profits after a certain threshold value. Only cooperative agreements with a strong degree of knowledge exchange above the threshold value provide a more efficient player with increasing profits. Therefore, if for some reasons the possible degree of cooperative knowledge exchange is limited from above, it is possible to observe a situation, when $R \& D$ cooperation is not an optimal solution. Also a situation can occur when both firms would rather share their knowledge completely while competing in production, than to form an RJV with partial knowledge exchange. 


\section{APPENDIX}

Proof. of Proposition 1. Let us consider the following linear quadratic game formulation with the states vector $z_{t}$ and the controls vector $u_{t}$. The firm $i$ considers the following maximization problem:

$$
\begin{aligned}
\max _{\left\{u_{i, t}\right\}} \pi_{i}^{*} & =L_{i, T}\left(z_{i, T}\right)+\sum_{t=0}^{T-1} L_{i, t}\left(z_{t}, u_{i, t}, u_{j, T}\right) \\
& =\omega_{i, t} z_{T}+\sum_{t=0}^{T-1}\left[\frac{1}{2} z_{t}^{\prime} W_{i, t} z_{t}+\omega_{i, t}^{\prime} z_{t}+\frac{1}{2} u_{i, t}^{\prime} \Lambda_{i, t} u_{i, t}+V_{i, t}\right]
\end{aligned}
$$

subject to

$$
\begin{aligned}
z_{i, t+1}= & A_{t} z_{t}+B_{i, t} u_{i, t}+B_{j, T} u_{j, T}, \\
& z_{i 0} \text { given, } \\
z_{t}= & \left(\begin{array}{c}
k_{i, t} \\
k_{j, T}
\end{array}\right), \quad u_{i, t}=\left(x_{i, t}\right), \\
i, j= & 1,2, \quad i \neq j, \quad t=0,1, \ldots T-1 .
\end{aligned}
$$

Assume that the firm's $i$ optimal profit stream in the given moment in time $\tau$ until the end of the game can be written in the following form:

$$
\pi_{i}^{*}(\tau)=\frac{1}{2} z_{\tau}^{\prime} K_{i \tau} z_{\tau}+p_{i \tau}^{\prime} z_{\tau}
$$

The firm's objective function at time $T-1$ is:

$$
\begin{aligned}
\pi_{i}^{*}(T-1) & =\max _{u_{i, T-1}}\left\{\pi_{i}^{*}(T)+L_{i, T-1}\left(z_{T-1}, u_{T-1}\right)\right\} \\
& =\max _{u_{i, T-1}}\left\{\frac{1}{2} z_{T}^{\prime} K_{i, t} z_{T}+p_{i, t}^{\prime} z_{T}\right. \\
& +\frac{1}{2} z_{T-1}^{\prime} W_{i, T-1} z_{T-1}+\omega_{i, t-1}^{\prime} z_{T-1} \\
& \left.+\frac{1}{2} u_{i, T-1}^{\prime} \Lambda_{i i, T-1} u_{i, T-1}+V_{i, T-1}\right\} .
\end{aligned}
$$

Expressions 2 and 1 give us:

$$
\begin{aligned}
\pi_{i}^{*}(T-1) & = \\
& \max _{u_{i, T-1}}\left\{\frac{1}{2}\left(A_{T-1} z_{T-1}+B_{i, T-1} u_{i, T-1}+B_{j, T-1} u_{j, T-1}\right)^{\prime} K_{i, t}\right. \\
& \times\left(A_{T-1} z_{T-1}+B_{i, T-1} u_{i, T-1}+B_{j, T-1} u_{j, T-1}\right) \\
& +p_{i, t}^{\prime}\left(A_{T-1} z_{T-1}+B_{i, T-1} u_{i, T-1}+B_{j, T-1} u_{j, T-1}\right) \\
& \left.+\frac{1}{2} z_{T-1}^{\prime} W_{i, T-1} z_{T-1}+\omega_{i, T-1}^{\prime} z_{T-1}+\frac{1}{2} u_{i, T-1}^{\prime} \Lambda_{i i, T-1} u_{i, T-1}+V_{i, T-1}\right\},
\end{aligned}
$$


which can be rewritten as

$$
\begin{aligned}
\pi_{i}^{*}(T-1) & = \\
& \max _{u_{i, T-1}}\left\{\frac{1}{2} z_{T-1}^{\prime} \Phi_{i, T-1} z_{T-1}+\phi_{i, T-1}^{\prime} z_{T-1}+z_{T-1}^{\prime} \Psi_{i, T-1} u_{i, T-1}+z_{T-1}^{\prime} \Psi_{j, T-1} u_{j, T-1}\right. \\
& +\frac{1}{2} u_{i, T-1}^{\prime} \Theta_{i i, T-1} u_{i, T-1}+u_{i, T-1}^{\prime} \Theta_{i j, T-1} u_{j, T-1}+\frac{1}{2} u_{j, T-1}^{\prime} \Theta_{j j, T-1} u_{j, T-1} \\
& \left.+\theta_{i, T-1}^{\prime} u_{i, T-1}+\theta_{j, T-1}^{\prime} u_{j, T-1}+V_{i, T-1}\right\},
\end{aligned}
$$

where

$$
\begin{aligned}
\Phi_{i, T-1} & =A_{T-1}^{\prime} K_{i, T} A_{T-1}+W_{i, T-1}, \\
\phi_{i, T-1} & =A_{T-1}^{\prime} p_{i, T}+\omega_{i, T-1}, \\
\Psi_{i, T-1} & =A_{T-1}^{\prime} K_{i, T} B_{i, T-1}, \\
\Psi_{j, T-1} & =A_{T-1}^{\prime} K_{i, T} B_{j, T-1}, \\
\Theta_{i i, T-1} & =B_{i, T-1}^{\prime} K_{i, T} B_{i, T-1}+\Lambda_{i i, T-1}, \\
\Theta_{i j, T-1} & =B_{i, T-1}^{\prime} K_{i, T} B_{j, T-1}, \\
\Theta_{j j, T-1} & =B_{j, T-1}^{\prime} K_{i, T} B_{j, T-1}, \\
\theta_{i, T-1}^{\prime} & =B_{i, T-1}^{\prime} p_{i, T}, \\
\theta_{j, T-1}^{\prime} & =B_{j, T-1}^{\prime} p_{i, T} .
\end{aligned}
$$

In a similar manner we can formalize the firm $j$ 's optimal profits stream:

$$
\begin{aligned}
\pi_{j}^{*}(T-1) & = \\
& \max _{u_{j, T}-1}\left\{\frac{1}{2} z_{T-1}^{\prime} \tilde{\Phi}_{j, T-1} z_{T-1}+\tilde{\phi}_{j, T-1}^{\prime} z_{T-1}+z_{T-1}^{\prime} \tilde{\Psi}_{j, T-1} u_{j, T-1}+z_{T-1}^{\prime} \tilde{\Psi}_{i, T-1} u_{i, T-1}\right. \\
& +\frac{1}{2} u_{j, T-1}^{\prime} \tilde{\Theta}_{j j, T-1} u_{j, T-1}+u_{j, T-1}^{\prime} \tilde{\Theta}_{j i, T-1} u_{i, T-1}+\frac{1}{2} u_{i, T-1}^{\prime} \tilde{\Theta}_{i i, T-1} u_{i, T-1} \\
& \left.+\tilde{\theta}_{j, T-1}^{\prime} u_{j, T-1}+\tilde{\theta}_{i, T-1}^{\prime} u_{i, T-1}+\tilde{V}_{j, T-1}\right\},
\end{aligned}
$$

where

$$
\begin{aligned}
\tilde{\Phi}_{j, T-1} & =A_{T-1}^{\prime} K_{j, T} A_{T-1}+W_{j, T-1}, \\
\tilde{\phi}_{j, T-1} & =A_{T-1}^{\prime} p_{j, T}+\omega_{j, T-1}, \\
\tilde{\Psi}_{i, T-1} & =A_{T-1}^{\prime} K_{j, T} B_{i, T-1}, \\
\tilde{\Psi}_{j, T-1} & =A_{T-1}^{\prime} K_{j, T} B_{j, T-1}, \\
\tilde{\Theta}_{i i, T-1} & =B_{i, T-1}^{\prime} K_{j, T} B_{i, T-1}, \\
\tilde{\Theta}_{j i, T-1} & =B_{j, T-1}^{\prime} K_{j, T} B_{i, T-1}, \\
\tilde{\Theta}_{j j, T-1} & =B_{j, T-1}^{\prime} K_{j, T} B_{j, T-1}+\Lambda_{j j, T-1}, \\
\tilde{\theta}_{i, T-1}^{\prime} & =B_{i, T-1}^{\prime} p_{j, T}, \\
\tilde{\theta}_{j, T-1}^{\prime} & =B_{j, T-1}^{\prime} p_{j, T} .
\end{aligned}
$$


Optimizing these problems simultaneously over $u_{T-1}$ we obtain the following set of first-order conditions

$$
\begin{array}{r}
\Psi_{i, T-1}^{\prime} z_{T-1}+\Theta_{i i, T-1} u_{i, T-1}+\Theta_{i j, T-1} u_{j, T-1}+\theta_{i, T-1}=0 \\
\tilde{\Psi}_{j, T-1}^{\prime} z_{T-1}+\tilde{\Theta}_{j i, T-1} u_{i, T-1}+\tilde{\Theta}_{j j, T-1} u_{j, T-1}+\tilde{\theta}_{j, T-1}=0
\end{array}
$$

or in matrix form

$$
\left(\begin{array}{cc}
\Theta_{i i, T-1} & \Theta_{i j, T-1} \\
\tilde{\Theta}_{j i, T-1} & \tilde{\Theta}_{j j, T-1}
\end{array}\right) u_{T-1}=-\left(\begin{array}{c}
\Psi_{i, T-1}^{\prime} \\
\tilde{\Psi}_{j, T-1}^{\prime}
\end{array}\right) z_{T-1}-\left(\begin{array}{c}
\theta_{i, T-1} \\
\tilde{\theta}_{j, T-1}
\end{array}\right) .
$$

The optimal feedback rules are obtained from (5) as

$$
u_{T-1}=G_{T-1} z_{T-1}+g_{T-1}
$$

where

$$
\begin{aligned}
G_{T-1} & =\left(\begin{array}{cc}
\Theta_{i i, T-1} & \Theta_{i j, T-1} \\
\tilde{\Theta}_{j i, T-1} & \tilde{\Theta}_{j j, T-1}
\end{array}\right)^{-1}\left(\begin{array}{c}
\Psi_{i, T-1}^{\prime} \\
\tilde{\Psi}_{j, T-1}^{\prime}
\end{array}\right), \\
g_{T-1} & =\left(\begin{array}{cc}
\Theta_{i i, T-1} & \Theta_{i j, T-1} \\
\tilde{\Theta}_{j i, T-1} & \tilde{\Theta}_{j j, T-1}
\end{array}\right)^{-1}\left(\begin{array}{c}
\theta_{i, T-1} \\
\tilde{\theta}_{j, T-1}
\end{array}\right),
\end{aligned}
$$

As we substitute (6) into (3) and (??) into (4), we obtain:

$$
\begin{aligned}
K_{i, T-1}= & \Phi_{i, T-1}+G_{T-1}^{\prime}\left(\begin{array}{ll}
\Theta_{i i, T-1} & \Theta_{i j, T-1} \\
\Theta_{i j, T-1} & \Theta_{j j, T-1}
\end{array}\right) G_{T-1}+2\left(\begin{array}{l}
\Psi_{i, T-1} \\
\Psi_{j, T-1}
\end{array}\right)^{\prime} G_{T-1}, \\
p_{i, T-1}= & \phi_{i, T-1}+\left(\begin{array}{l}
\Psi_{i, T-1} \\
\Psi_{j, T-1}
\end{array}\right)^{\prime} g_{T-1}+G_{T-1}^{\prime}\left(\begin{array}{ll}
\Theta_{i i, T-1} & \Theta_{i j, T-1} \\
\Theta_{i j, T-1} & \Theta_{j j, T-1}
\end{array}\right) g_{T-1} \\
& +G_{T-1}^{\prime}\left(\begin{array}{l}
\theta_{i, T-1} \\
\theta_{j, T-1}
\end{array}\right),
\end{aligned}
$$

and

$$
\begin{aligned}
K_{j, T-1}= & \tilde{\Phi}_{j, T-1}+G_{T-1}^{\prime}\left(\begin{array}{cc}
\tilde{\Theta}_{i i, T-1} & \tilde{\Theta}_{j i, T-1} \\
\tilde{\Theta}_{j i, T-1} & \tilde{\Theta}_{j j, T-1}
\end{array}\right) G_{T-1}+2\left(\begin{array}{c}
\tilde{\Psi}_{i, T-1} \\
\tilde{\Psi}_{j, T-1}
\end{array}\right)^{\prime} G_{T-1}, \\
p_{j, T-1} & =\tilde{\phi}_{i, T-1}+\left(\begin{array}{c}
\tilde{\Psi}_{i, T-1} \\
\tilde{\Psi}_{j, T-1}
\end{array}\right)^{\prime} g_{T-1}+G_{T-1}^{\prime}\left(\begin{array}{cc}
\tilde{\Theta}_{i i, T-1} & \tilde{\Theta}_{j i, T-1} \\
\tilde{\Theta}_{j i, T-1} & \tilde{\Theta}_{j j, T-1}
\end{array}\right) g_{T-1} \\
& +G_{T-1}^{\prime}\left(\begin{array}{c}
\tilde{\theta}_{i, T-1} \\
\tilde{\theta}_{j, T-1}
\end{array}\right) .
\end{aligned}
$$

Repeating these steps for time period $T-2$ and further we obtain the solution for the given dynamic game. The problem is solved numerically by integrating the Riccati equations for $K$ and $p((? ?)$ and (??)) backwards from the terminal conditions. Using the feedback matrices (7) we integrate forward in time from the initial state $z_{0}$ to obtain the optimal control trajectory $u_{t}$ and the state trajectory $z_{t}, t \in[0, T]$. 


\section{References}

Amir, R., I. Evstigneev, and J. Wooders (2003), Noncooperative vs Cooperative R\&D with Endogenous Spillover Rates, Games and Economic Behavior, 42, pp. 183-207.

d'Aspremont, C. and A. Jacquemin (1988), Cooperative and Noncooperative R\&D in Duopoly with Spillovers, The American Economic Review, 78, pp. 11331137.

Basar, T. and G. Olsder (1989), Dynamic Noncooperative Game Theory, Academic Press.

Brod, A. and R. Shivakumar (1997), R\&D Cooperation and the Joint Exploitation of R\&D, Canadian Journal of Economics, 30, pp. 673-684.

Doraszelski, U. (2003), An R\&D Race with Knowledge Accumulation, Rand Journal of Economics, Vol. 34, pp. 19-41.

Hinloopen J. (2000), Strategic R\&D Co-operatives, Research in Economics, 54, pp. 153-185.

Kamien M. and I. Zang (2000), Meet Me Halfway: Research Joint Ventures and Absorptive Capacity, International Journal of Industrial Organization, 18, pp. 995-1012.

Kendrick, D. (1987), Control Theory with Application to Economics, Chapter 4 in the Handbook of Mathematical Economics (ed. K.J. Arrow and M.D. Intriligator), Vol. 1, pp. 111-158.

Kline J. (2000), Research Joint Ventures and the Cost Paradox, International Journal of Industrial Organization, 18, pp. 1049-1065.

Petit, M. L. and B. Tolwinsky (1999), R\&D Cooperation or Competition?, European Economic Review, 43, pp. 185-208.

Reinganum J. (1981), Dynamic Games of Innovation, Journal of Economic Theory, 25, pp. 21-41.

Salant, S. W. and G. Shaffer (1998), Optimal Asymmetric Strategies in Research Joint Ventures, International Journal of Industrial Organization, 16, pp. 195-208.

Suzumura, K. (1992), Cooperative and Noncooperative R\&D in an Oligopoly with Spillovers, American Economic Review, 82, pp. 1307-1320.

Vonortas N. (1994), Inter-firm Cooperation with Imperfect Appropriable Research, International Journal of Industrial Organization, 12, pp. 413-435. 


\title{
CESifo Working Paper Series
}

\author{
(for full list see www.cesifo.de)
}

1329 Chiona Balfoussia and Mike Wickens, Macroeconomic Sources of Risk in the Term Structure, November 2004

1330 Ludger Wößmann, The Effect Heterogeneity of Central Exams: Evidence from TIMSS, TIMSS-Repeat and PISA, November 2004

1331 M. Hashem Pesaran, Estimation and Inference in Large Heterogeneous Panels with a Multifactor Error Structure, November 2004

1332 Maarten C. W. Janssen, José Luis Moraga-González and Matthijs R. Wildenbeest, A Note on Costly Sequential Search and Oligopoly Pricing, November 2004

1333 Martin Peitz and Patrick Waelbroeck, An Economist's Guide to Digital Music, November 2004

1335 Lutz Hendricks, Why Does Educational Attainment Differ Across U.S. States?, November 2004

1336 Jay Pil Choi, Antitrust Analysis of Tying Arrangements, November 2004

1337 Rafael Lalive, Jan C. van Ours and Josef Zweimueller, How Changes in Financial Incentives Affect the Duration of Unemployment, November 2004

1338 Robert Woods, Fiscal Stabilisation and EMU, November 2004

1339 Rainald Borck and Matthias Wrede, Political Economy of Commuting Subsidies, November 2004

1340 Marcel Gérard, Combining Dutch Presumptive Capital Income Tax and US Qualified Intermediaries to Set Forth a New System of International Savings Taxation, November 2004

1341 Bruno S. Frey, Simon Luechinger and Alois Stutzer, Calculating Tragedy: Assessing the Costs of Terrorism, November 2004

1342 Johannes Becker and Clemens Fuest, A Backward Looking Measure of the Effective Marginal Tax Burden on Investment, November 2004

1343 Heikki Kauppi, Erkki Koskela and Rune Stenbacka, Equilibrium Unemployment and Capital Intensity Under Product and Labor Market Imperfections, November 2004

1344 Helge Berger and Till Müller, How Should Large and Small Countries Be Represented in a Currency Union?, November 2004

1345 Bruno Jullien, Two-Sided Markets and Electronic Intermediaries, November 2004 
1346 Wolfgang Eggert and Martin Kolmar, Contests with Size Effects, December 2004

1347 Stefan Napel and Mika Widgrén, The Inter-Institutional Distribution of Power in EU Codecision, December 2004

1348 Yin-Wong Cheung and Ulf G. Erlandsson, Exchange Rates and Markov Switching Dynamics, December 2004

1349 Hartmut Egger and Peter Egger, Outsourcing and Trade in a Spatial World, December 2004

1350 Paul Belleflamme and Pierre M. Picard, Piracy and Competition, December 2004

1351 Jon Strand, Public-Good Valuation and Intrafamily Allocation, December 2004

1352 Michael Berlemann, Marcus Dittrich and Gunther Markwardt, The Value of NonBinding Announcements in Public Goods Experiments: Some Theory and Experimental Evidence, December 2004

1353 Camille Cornand and Frank Heinemann, Optimal Degree of Public Information Dissemination, December 2004

1354 Matteo Governatori and Sylvester Eijffinger, Fiscal and Monetary Interaction: The Role of Asymmetries of the Stability and Growth Pact in EMU, December 2004

1355 Fred Ramb and Alfons J. Weichenrieder, Taxes and the Financial Structure of German Inward FDI, December 2004

1356 José Luis Moraga-González and Jean-Marie Viaene, Dumping in Developing and Transition Economies, December 2004

1357 Peter Friedrich, Anita Kaltschütz and Chang Woon Nam, Significance and Determination of Fees for Municipal Finance, December 2004

1358 M. Hashem Pesaran and Paolo Zaffaroni, Model Averaging and Value-at-Risk Based Evaluation of Large Multi Asset Volatility Models for Risk Management, December 2004

1359 Fwu-Ranq Chang, Optimal Growth and Impatience: A Phase Diagram Analysis, December 2004

1360 Elise S. Brezis and François Crouzet, The Role of Higher Education Institutions: Recruitment of Elites and Economic Growth, December 2004

1361 B. Gabriela Mundaca and Jon Strand, A Risk Allocation Approach to Optimal Exchange Rate Policy, December 2004

1362 Christa Hainz, Quality of Institutions, Credit Markets and Bankruptcy, December 2004 
1363 Jerome L. Stein, Optimal Debt and Equilibrium Exchange Rates in a Stochastic Environment: an Overview, December 2004

1364 Frank Heinemann, Rosemarie Nagel and Peter Ockenfels, Measuring Strategic Uncertainty in Coordination Games, December 2004

1365 José Luis Moraga-González and Jean-Marie Viaene, Anti-Dumping, Intra-Industry Trade and Quality Reversals, December 2004

1366 Harry Grubert, Tax Credits, Source Rules, Trade and Electronic Commerce: Behavioral Margins and the Design of International Tax Systems, December 2004

1367 Hans-Werner Sinn, EU Enlargement, Migration and the New Constitution, December 2004

1368 Josef Falkinger, Noncooperative Support of Public Norm Enforcement in Large Societies, December 2004

1369 Panu Poutvaara, Public Education in an Integrated Europe: Studying to Migrate and Teaching to Stay?, December 2004

1370 András Simonovits, Designing Benefit Rules for Flexible Retirement with or without Redistribution, December 2004

1371 Antonis Adam, Macroeconomic Effects of Social Security Privatization in a Small Unionized Economy, December 2004

1372 Andrew Hughes Hallett, Post-Thatcher Fiscal Strategies in the U.K.: An Interpretation, December 2004

1373 Hendrik Hakenes and Martin Peitz, Umbrella Branding and the Provision of Quality, December 2004

1374 Sascha O. Becker, Karolina Ekholm, Robert Jäckle and Marc-Andreas Mündler, Location Choice and Employment Decisions: A Comparison of German and Swedish Multinationals, January 2005

1375 Christian Gollier, The Consumption-Based Determinants of the Term Structure of Discount Rates, January 2005

1376 Giovanni Di Bartolomeo, Jacob Engwerda, Joseph Plasmans, Bas van Aarle and Tomasz Michalak, Macroeconomic Stabilization Policies in the EMU: Spillovers, Asymmetries, and Institutions, January 2005

1377 Luis H. R. Alvarez and Erkki Koskela, Progressive Taxation and Irreversible Investment under Uncertainty, January 2005

1378 Theodore C. Bergstrom and John L. Hartman, Demographics and the Political Sustainability of Pay-as-you-go Social Security, January 2005 
1379 Bruno S. Frey and Margit Osterloh, Yes, Managers Should Be Paid Like Bureaucrats, January 2005

1380 Oliver Hülsewig, Eric Mayer and Timo Wollmershäuser, Bank Loan Supply and Monetary Policy Transmission in Germany: An Assessment Based on Matching Impulse Responses, January 2005

1381 Alessandro Balestrino and Umberto Galmarini, On the Redistributive Properties of Presumptive Taxation, January 2005

1382 Christian Gollier, Optimal Illusions and Decisions under Risk, January 2005

1383 Daniel Mejía and Marc St-Pierre, Unequal Opportunities and Human Capital Formation, January 2005

1384 Luis H. R. Alvarez and Erkki Koskela, Optimal Harvesting under Resource Stock and Price Uncertainty, January 2005

1385 Ruslan Lukach, Peter M. Kort and Joseph Plasmans, Optimal R\&D Investment Strategies with Quantity Competition under the Threat of Superior Entry, January 2005

1386 Alfred Greiner, Uwe Koeller and Willi Semmler, Testing Sustainability of German Fiscal Policy. Evidence for the Period 1960 - 2003, January 2005

1387 Gebhard Kirchgässner and Tobias Schulz, Expected Closeness or Mobilisation: Why Do Voters Go to the Polls? Empirical Results for Switzerland, 1981 - 1999, January 2005

1388 Emanuele Bacchiocchi and Alessandro Missale, Managing Debt Stability, January 2005

1389 Assar Lindbeck and Dirk Niepelt, Improving the SGP: Taxes and Delegation rather than Fines, January 2005

1390 James J. Heckman and Dimitriy V. Masterov, Skill Policies for Scotland, January 2005

1391 Emma Galli \& Fabio Padovano, Sustainability and Determinants of Italian Public Deficits before and after Maastricht, January 2005

1392 Angel de la Fuente and Juan Francisco Jimeno, The Private and Fiscal Returns to Schooling and the Effect of Public Policies on Private Incentives to Invest in Education: A General Framework and Some Results for the EU, January 2005

1393 Juan C. Conesa and Carlos Garriga, Optimal Response to a Demographic Shock, January 2005

1394 Christian Gollier, Optimal Portfolio Management for Individual Pension Plans, February 2005

1395 Ruslan Lukach, Joseph Plasmans and Peter M. Kort, Innovation Strategies in a Competitive Dynamic Setting, February 2005 